\title{
Benefits and obstacles of telemetric ICP monitoring
}

\author{
Joachim M. K. Oertel ${ }^{1}$ (D) $\cdot$ Matthias J. M. Huelser ${ }^{1}$
}

Received: 15 January 2021 / Accepted: 21 January 2021 / Published online: 7 February 2021

(C) The Author(s) 2021

The commercial use of telemetric intracranial pressure (ICP) monitoring has been in use for over a decade now. The first device which was licensed is the Neurovent-P-tel probe ${ }^{\circledR}$ (Raumedic, Helmbrecht, Germany) in 2009 followed by reports of its first clinical use [2, 3, 8, 24]. Preclinical studies showed a sufficient long-term stability of the ICP measurement with only a minimal zero drift with good accuracy $[9,11$, 12].

The second device followed with the Sensor Reservoir® which was approved for clinical use in 2015 (Christoph Miethke GmbH \& Co.KG, Potsdam, Germany). The Sensor Reservoir $\AA$ is to be integrated into the shunt system, and there is no limitation about the approved implantation time in opposition to the P-tel probe whose approved implantation time is limited to 90 days. The first experience with its clinical use was published in 2017 [6], and the first larger study appeared in an article in 2018 describing the experience of one of its biggest technical potentials - the intracranial pressure-guided shunt valve adjustment [1].

Nowadays, telemetric ICP monitoring is feasible and useable for a wide spectrum of pathologies.

First of all, compared to conventional ICP monitoring methods, it has the advantage of being a closed system decreasing the risk of infection [3,13]. This is particularly an argument for using the P-tel device for ICP monitoring in the neuro-intensive care setting which is usually the application field for cabled ICP probes $[15,21]$.

In addition, the closed system and the long capable implantation duration facilitate different areas of application.

This article is part of the Topical Collection on CSF Circulation

Joachim M. K. Oertel

oertelj@freenet.de

1 Department of Neurosurgery, Saarland University Medical Center and Saarland University Faculty of Medicine, Homburg, Saarland, Germany
Long-term ICP monitoring with the Neurovent-P-tel $®$ after ETV for 8 to 12 weeks is especially useful for treatment response prediction since the average time of ETV failure occurs within this time period $[4,10,23]$.

Furthermore, it is a helpful tool for the diagnosis and prediction of shunt responsiveness in patients with complex hydrocephalus and ICP-related diseases, like idiopathic intracranial hypertension - in both adults and children $[2,14,19,20]$.

Additionally, it allows the monitoring of the shunt effect and the verification of a proper shunt function over a longer time period in complex shunt patients $[1,2,19,20]$.

Beyond that, the possibility of doing measurements in supine and vertical positions and over several measurement periods provides a clear distinction between over- and underdrainage. The potential of ICP-guided optimization of valve setting can be exploited to full extent due to use of both adjustable differential and anti-gravitational valves $[1,8,18-20]$, which even a reduction in surgical revisions and radiation exposure due to a reduced necessity of imaging can be achieved [19]. Also, it provides a lower rate of hospitalization and there is even an alternative for home-telemonitoring [17, 19, 22].

"Does it change management" ask the authors of the study presented in the following, where a series of twelve shunt treated patients before and after insertion of a Sensor Reservoir ${ }^{\circledR}$ were investigated. Without giving away too much of the answer provided by this study, the authors found an improvement of symptoms in $75 \%$ of patients, a reduction of radiation exposure and hospitalization, and increased cost-effectiveness, similar to results which previous studies have yielded $[1,5,19]$.

But telemetric ICP measurement also has its limitations and disadvantages.

First of all, the sampling frequency is significantly lower compared to cable bound devices (Shunt Reservoir ${ }^{\circledR} 40 \mathrm{~Hz}$, Neurovent-P-tel $\left.\AA^{5} \mathrm{~Hz}\right)$. A single pressure curve analysis is therefore not possible, although measurement of pulse pressure amplitude with both devices is feasible. A further obstacle is the risk of zero drifting which obviously threatens the accuracy of the results. This problem occurs not only in 
telemetric ICP monitoring but also in conventional measurement. Nevertheless, because of the long durability of the implant, the time-dependent risk is higher in telemetric than in conventional measurements. The median shift from the baseline was in a study with P-tel® devices $2.5 \mathrm{mmHg}$ on average (implantation time was often longer than the CE-approval time of 90 days) [16]. Therefore, analyzing dynamic ICP values like vasogenic slow waves and the pulse pressure amplitude is much more essential than static ICP values like the mean ICP [7]. Gathering this information is feasible with both devices but its analysis is not automatically done and therefore depends on the experience of the neurosurgeon and is time consuming. And in the case of the Shunt Sensor $®$, there is so far a lack of an appropriate analysis program. Here is room for improvement.

Nevertheless, telemetric ICP monitoring is already a valuable tool. The choice of the most suitable device depends on diagnostic goal in the individual case: for long-duration measurements, for example, for diagnostic purposes or for monitoring response to ETV, the Neurovent-P-tel ${ }^{\circledR}$ is to be preferred. For continuous, repeated ambulatory follow-up measurements intending to verify subtle drainage-related shunt failure and to control the valve setting adjustment in sequential outpatient presentations over years the Shunt Sensor® is more suitable.

Funding Open Access funding enabled and organized by Projekt DEAL.

Open Access This article is licensed under a Creative Commons Attribution 4.0 International License, which permits use, sharing, adaptation, distribution and reproduction in any medium or format, as long as you give appropriate credit to the original author(s) and the source, provide a link to the Creative Commons licence, and indicate if changes were made. The images or other third party material in this article are included in the article's Creative Commons licence, unless indicated otherwise in a credit line to the material. If material is not included in the article's Creative Commons licence and your intended use is not permitted by statutory regulation or exceeds the permitted use, you will need to obtain permission directly from the copyright holder. To view a copy of this licence, visit http://creativecommons.org/licenses/by/4.0/.

\section{References}

1. Antes S, Stadie A, Muller S, Linsler S, Breuskin D, Oertel J (2018) Intracranial pressure-guided shunt valve adjustments with the Miethke sensor reservoir. World Neurosurg 109:e642-e650. https://doi.org/10.1016/j.wneu.2017.10.044

2. Antes S, Tschan CA, Heckelmann M, Breuskin D, Oertel J (2016) Telemetric intracranial pressure monitoring with the raumedic Neurovent P-tel. World Neurosurg 91:133-148. https://doi.org/10. 1016/j.wneu.2016.03.096

3. Antes S, Tschan CA, Kunze G, Ewert L, Zimmer A, Halfmann A, Oertel J (2014) Clinical and radiological findings in long-term intracranial pressure monitoring. Acta Neurochir (Wien) 156:10091019; discussion 1019. https://doi.org/10.1007/s00701-013-1991-7
4. Antes S, Tschan CA, Oertel JM (2014) An operative technique combining endoscopic third ventriculostomy and long-term ICP monitoring. Childs Nerv Syst 30:331-335. https://doi.org/10. 1007/s00381-013-2269-3

5. Barber JM, Pringle CJ, Raffalli-Ebezant H, Pathmanaban O, Ramirez R, Kamaly-Asl ID (2017) Telemetric intra-cranial pressure monitoring: clinical and financial considerations. $\mathrm{Br}$ J Neurosurg 31:300-306. https://doi.org/10.1080/02688697. 2016.1229752

6. Ertl P, Hermann EJ, Heissler HE, Krauss JK (2017) Telemetric intracranial pressure recording via a shunt system integrated sensor: a safety and feasibility study. J Neurol Surg A Cent Eur Neurosurg 78:572-575. https://doi.org/10.1055/s-00371603632

7. Evensen KB, Eide PK (2020) Measuring intracranial pressure by invasive, less invasive or non-invasive means: limitations and avenues for improvement. Fluids Barriers CNS 17:34. https://doi.org/ 10.1186/s12987-020-00195-3

8. Freimann FB, Schulz M, Haberl H, Thomale UW (2014) Feasibility of telemetric ICP-guided valve adjustments for complex shunt therapy. Childs Nerv Syst 30:689-697. https://doi.org/10.1007/s00381013-2324-0

9. Freimann FB, Sprung C, Chopra SS, Vajkoczy P, Wolf S (2013) Large-scale referencing of the telemetric neurovent-P-tel intracranial pressure sensor in a porcine model. Pediatr Neurosurg 49:29-32. https://doi.org/10.1159/000355561

10. Grand W, Leonardo J, Chamczuk AJ, Korus AJ (2016) Endoscopic third ventriculostomy in 250 adults with hydrocephalus: patient selection, outcomes, and complications. Neurosurgery 78:109-119. https://doi.org/10.1227/NEU. 0000000000000994

11. Kiefer M, Antes S, Leonhardt S, Schmitt M, Orakcioglu B, Sakowitz OW, Eymann R (2012) Telemetric ICP measurement with the first CE-approved device: data from animal experiments and initial clinical experiences. Acta Neurochir Suppl 114:111-116. https://doi.org/10.1007/978-3-7091-09564_20

12. Kiefer M, Antes S, Schmitt M, Krause I, Eymann R (2011) Longterm performance of a CE-approved telemetric intracranial pressure monitoring. Conf Proc IEEE Eng Med Biol Soc 2011:2246-2249. https://doi.org/10.1109/IEMBS.2011.6090426

13. Kitchen WJ, Singh N, Hulme S, Galea J, Patel HC, King AT (2011) External ventricular drain infection: improved technique can reduce infection rates. Br J Neurosurg 25:632-635. https://doi.org/10. 3109/02688697.2011.578770

14. Korfias SI, Banos S, Alexoudi A, Themistoklis K, Vlachakis E, Patrikelis P, Gatzonis S, Sakas DE (2020) Telemetric intracranial pressure monitoring: our experience with 22 patients investigated for intracranial hypertension. Br J Neurosurg 1-12. https://doi.org/ 10.1080/02688697.2020.1849544

15. Lilja-Cyron A, Kelsen J, Andresen M, Fugleholm K, Juhler M (2018) Feasibility of telemetric intracranial pressure monitoring in the neuro intensive care unit. J Neurotrauma 35:1578-1586. https:// doi.org/10.1089/neu.2017.5589

16. Norager NH, Lilja-Cyron A, Bjarkam CR, Duus S, Juhler M (2018) Telemetry in intracranial pressure monitoring: sensor survival and drift. Acta Neurochir (Wien) 160:2137-2144. https://doi.org/10. 1007/s00701-018-3691-9

17. Oertel JMK, Huelser MJM (2019) Telemetric home monitoring of intracranial pressure-where are we now. Acta Neurochir (Wien) 161:1603-1604. https://doi.org/10.1007/s00701-01903962-w

18. Oertel JMK, Huelser MJM (2020) Is there an ideal shunt valve and opening pressure setting for NPH? Acta Neurochir (Wien) 162:2965-2966. https://doi.org/10.1007/s00701-02004598-x 
19. Pedersen SH, Norager NH, Lilja-Cyron A, Juhler M (2019) Telemetric intracranial pressure monitoring in children. Childs Nerv Syst. https://doi.org/10.1007/s00381-019-042714

20. Pennacchietti V, Prinz V, Schaumann A, Finger T, Schulz M, Thomale UW (2020) Single center experiences with telemetric intracranial pressure measurements in patients with CSF circulation disturbances. Acta Neurochir (Wien) 162:2487-2497. https://doi. org/10.1007/s00701-020-04421-7

21. Rot S, Dweek M, Gutowski P, Goelz L, Meier U, Lemcke J (2020) Comparative investigation of different telemetric methods for measuring intracranial pressure: a prospective pilot study. Fluids Barriers CNS 17:63. https://doi.org/10.1186/s12987-020-00225-0

22. Tschan CA, Velazquez Sanchez VF, Heckelmann M, Antes S (2019) Home telemonitoring of intracranial pressure. Acta
Neurochir (Wien) 161:1605-1617. https://doi.org/10.1007/ s00701-019-03959-5

23. Waqar M, Ellenbogen JR, Stovell MG, Al-Mahfoudh R, Mallucci C, Jenkinson MD (2016) Long-term outcomes of endoscopic third ventriculostomy in adults. World Neurosurg 94:386-393. https:// doi.org/10.1016/j.wneu.2016.07.028

24. Welschehold S, Schmalhausen E, Dodier P, Vulcu S, Oertel J, Wagner W, Tschan CA (2012) First clinical results with a new telemetric intracranial pressure-monitoring system. Neurosurgery 70:44-49; discussion 49. https://doi.org/10.1227/NEU. 0b013e31822dda12

Publisher's note Springer Nature remains neutral with regard to jurisdictional claims in published maps and institutional affiliations. 